\title{
Una mujer con alteración de las uñas (retroniquia)
}

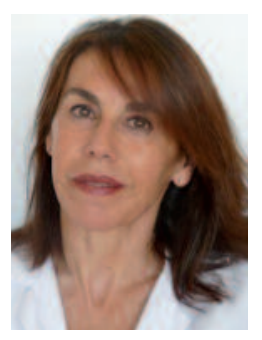

\section{Lourdes Navarro} Campoamor Especialista en Dermatología y Venereología. Miembro del Grupo Español de Tricología y Onicología de la AEDV. Hospital Beata Maㅗ Ana. Madrid.
Mi paciente es una mujer de 29 años de edad que, después de un esmaltado permanente, nota que la uña del primer dedo del pie izquierdo no crece como las otras y, al retirar el esmalte, tiene un color amarillo, pero sin síntomas. Pasados unos meses, después de caminar con más intensidad, comienza con dolor e inflamación de la piel proximal que rodea a esa uña (fig. 1-A). Al mismo tiempo, se inicia el confinamiento por la COVID19 en España, por lo que se pone en contacto con el dermatólogo por vía teledermatológica. Como antecedentes personales, presenta una coalición tarsal bilateral, pies valgos y crisis de ausencias o de pequeño mal en tratamiento desde los 11 hasta los 22 años de edad.
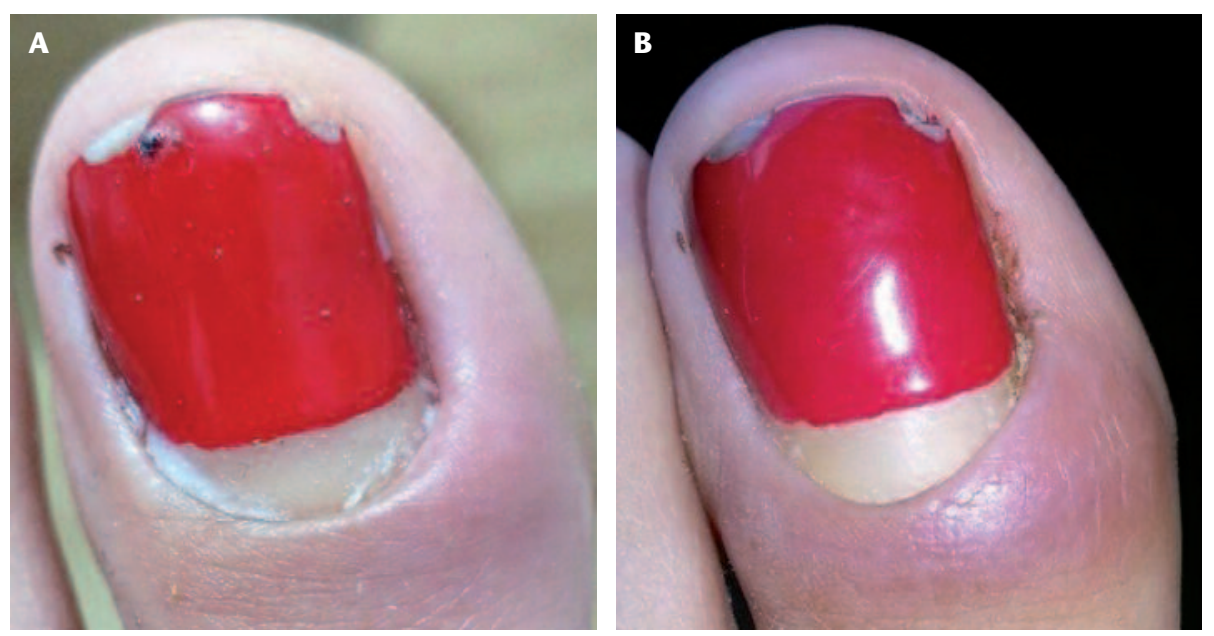

Figura 1. A. Eritema y edema periungueal proximal. B. Aumento de la sintomatología sin crecimiento de la uña.
En la exploración fotográfica, se aprecia un leve eritema e inflamación en los pliegues lateral y proximal de la uña (fig.1-A). El esmaltado revela que la uña había estado creciendo. Al mes y medio (fig. 1-B), el dolor y la inflamación eran más intensos, sin crecimiento de la uña. Se le pautó propionato de clobetasol de $0,5 \mathrm{mg} / \mathrm{g}$ en el pliegue proximal en cura oclusiva nocturna, notando mejoría de la sintomatología y cambios en la uña que estaban ocultos por el esmalte: xantoniquia (color amarillento) proximal y distrofia media distal de la uña (granulación de queratina de la uña) (fig. 2). Se solicitó una ecografía (fig. 3).

La sospecha diagnóstica con la historia clínica y las imágenes remitidas 

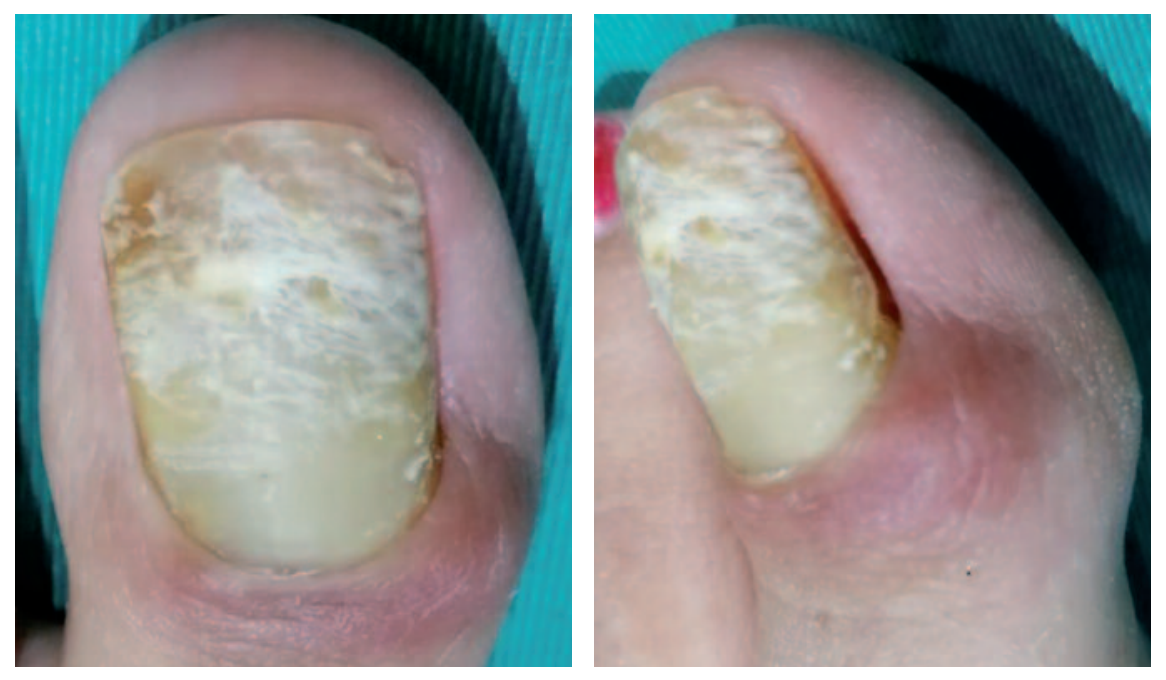

Figura 2. Eritema en el pliegue proximal, xantoniquia y granulación de queratina en la zona media distal de la uña.
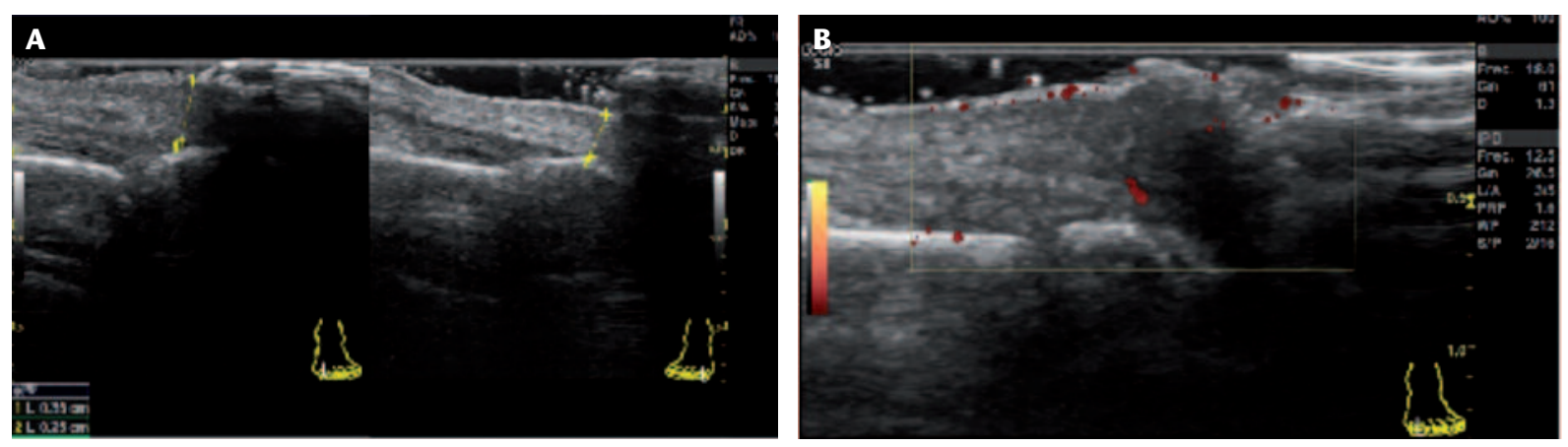

Figura 3. A. Comparativa del engrosamiento del pliegue proximal del pie izquierdo (mide 3,5 mm) frente al contralateral (mide 2,5 mm). B. Aumento de vascularización en el pliegue proximal.

(Cortesía de la Dra. Segura Grau).

por la paciente fue de retroniquia. El término 'retroniquia' está formado por retro, del latín «hacia atrás», y onychia, del griego «uña», es decir, se trata de un crecimiento hacia atrás de la uña. Descrita por primera vez por De Berker y Rendall, en 2008 apareció la primera serie de casos publicados ${ }^{1,2}$. La uña queda atrapada en el pliegue proximal, provocando inflamación, dolor y detención del crecimiento de la uña, y se van generando uñas debajo del pliegue proximal.

Es una afección frecuente, pero escasamente diagnosticada, porque se suele confundir con una paroniquia. Es más habitual en los dedos de los pies y en mujeres en la edad media de la vida, que en adolescentes y niños, y en los dedos de las manos. En el $84 \%$ de los casos descritos, es unilateral, pero puede ser bilateral ${ }^{3}$.

Se han mencionado varios agentes causales: microtraumatismos de repetición (deporte, calzado inapropiado, alteraciones mecánicas del pie y otras), traumatismo agudo, procesos sistémicos (tromboflebitis, osteoartritis, anorexia, síndrome compartimental), fármacos y causas hereditarias; en otras ocasiones, no se ha encontrado una causa. Muchos de estos factores etiológicos son comunes a las líneas de Beau y la onicomadesis. 
Es posible que un traumatismo agudo o traumatismos de repetición ejerzan una fuerza sobre el borde libre distal de la lámina ungueal y provoquen la aparición de retroniquia. Son diferentes las propuestas fisiopatológicas. De Berker et al. describen cómo una contusión empuja a la uña hacia atrás, causando una pérdida de la alineación de la uña y una alteración de su crecimiento longitudinal, mientras persiste un firme contacto de la uña con los pliegues laterales y el lecho ungueal ${ }^{2}$. Sin embargo, Haneke et al. consideran que lo primordial es la onicólisis, que hace que la uña pueda ser empujada hacia atrás dentro del pliegue proximal, dañándolo ${ }^{3}$. Otros postulan que un daño isquémico es la principal causa de la pérdida de continuidad entre la matriz y la lámina de la uña ${ }^{4}$. Está claro que a la onicólisis proximal y/o distal se le añade algún factor que mantiene la uña previa solapada al pliegue proximal y no puede ser eliminada.

La clínica primordial es la detención del crecimiento de la uña y la persistencia de una inflamación del pliegue proximal dolorosa. En la exploración física, observamos un pliegue proximal inflamado y elevado, más evidente desde una visión lateral, la lámina engrosada y de color amarillo en la zona proximal, xantoniquia y, si persiste el cuadro, la aparición de tejido de granulación en el pliegue proximal. La xantoniquia se debe a la detención del crecimiento, la onicólisis proximal, la nueva uña debajo de la uña vieja y el exudado inflamatorio en el pliegue proximal. Dependiendo del momento evolutivo, hay dos estadios: a) fase inicial o estadio 1, en que hay una interrupción del crecimiento de la uña, con dolor, discreta paroniquia, exudado debajo del pliegue proximal y xantoniquia; y b) fase tardía o estadio 2, donde los síntomas anteriores están presentes de forma más intensa ${ }^{4,5}$. En fases más avanzadas, la inflamación no es tan exagerada, continúa el dolor, es más evidente la xantoniquia, y se produce distrofia ungueal transversal, microniquia, onicólisis distal y acortamiento del lecho ungueal. El retraso en el diag- nóstico puede favorecer la sobreinfección bacteriana.

Para el diagnóstico, es fundamental la sospecha clínica. La ecografía es de gran utilidad para excluir otras alteraciones inflamatorias e infecciosas y patología tumoral, además de poner de manifiesto las alteraciones fisiopatológicas de la retroniquia. En la ecografía, se observa un halo hipoecogénico que rodea el origen de la uña, un acortamiento de la distancia entre el inicio de la uña y la base de la falange distal, la presencia de varias láminas ungueales superpuestas en el pliegue proximal y áreas parcheadas en la parte ventral de la lámina sin afectación de la dorsal ${ }^{5,6}$ (fig. 3).

La actitud terapéutica está condicionada por el momento evolutivo de la retroniquia. El tratamiento conservador es para las fases iniciales y en los pacientes que rechazan la cirugía; se recomienda la aplicación de corticoides potentes, en cura oclusiva, en el pliegue proximal durante 4-8 semanas $^{7,8}$. Si pasadas 10 semanas del tratamiento no hay mejoría, y en retroniquias más intensas y evolucionadas, se indica la avulsión total de la uña ${ }^{8}$. Además, es necesario controlar el crecimiento posterior de la uña, realizar un estudio biomecánico del pie y sugerir un calzado adecuado a la morfología del pie. Después del tratamiento, la uña crece correctamente, pero la retroniquia puede recurrir y, en un 13-33\% de los casos, puede quedar una distrofia permanente de la uña $a^{4,5}$.

El conocimiento de esta entidad evitará la demora en el diagnóstico y la realización de tratamientos innecesarios con antibióticos y antifúngicos. Así fue en nuestra paciente, demostrando que la asistencia rápida, incluso a distancia, con teledermatología, tiene, además, un valor añadido: la disminución de la ansiedad que provoca el aislamiento durante el confinamiento, medida preventiva de la expansión de las pandemias.

\section{BIBLIOGRAFÍA}

1. de Berker DA, Rendall JR. Retronychia-Proximal ingrowing nail. J Eur Acad Dermatol Venereol. 1999;12:S126. 
2. de Berker DA, Richert B, Duhard E, Piraccini BM, André J, Baran R. Retronychia: proximal ingrowing of the nail plate. J Am Acad Dermatol. 2008;58(6):978-83.

3. Ventura F, Correia O, Duarte AF, Barros AM, Haneke E. "Retronychia--clinical and pathophysiological aspects". J Eur Acad Dermatol Venereol. 2016;30(1):16-9.

4. Gerard E, Prevezas C, Doutre MS, Beylot-Barry M, Cogrel O. Risk factors, clinical variants and therapeutic outcome of retronychia: a retrospective study of 18 patients. Eur J Dermatol. 2016;26(4):377-81.

5. Litaiem N, Drissi H, Zeglaoui F, Khachemoune A. Retronychia of the toenails: a review with emphasis on pathogenesis, new diagnostic and management trends. Arch Dermatol Res. 2019;311(7):505-12.

6. Fernández J, Reyes-Baraona F, Wortsman X. Ultrasonographic criteria for diagnosing unilateral and bilateral retronychia. J Ultrasound Med. 2018;37(5):1201-9.

7. Lencastre A, lorizzo M, Caucanas M, Cunha N, Trakatelli MG, Zaraa I, et al. Topical steroids for the treatment of retronychia. J Eur Acad Dermatol Venereol. 2019;33(9):e320-2.

8. Laird ME, Lo Sicco KI, Rich P. Conservative treatment of retronychia: a retrospective study of 25 patients. Dermatol Surg. 2019;45(4):614-6. 